\title{
Direct Torque Control of Two Induction Motors Using the Nine-Switch Inverter
}

\author{
Draoui Abdelghani', Allaoua Boumediène ${ }^{2}$ \\ ${ }^{1}$ Laboratoire de Commande, Analyse et Optimisation des Systèmes Electro-Energétiques (CAOSEE), UTMB, Algeria \\ ${ }^{2}$ Department of Electrical Engineering, University of Tahri Mohammed, Algeria
}

\begin{tabular}{l}
\hline Article Info \\
\hline Article history: \\
Received Jul 24, 2018 \\
Revised Sep 11, 2018 \\
Accepted Sep 15, 2018 \\
\hline
\end{tabular}

\section{Keyword:}

DTC

Induction motor

SVM

EV

\begin{abstract}
The Nine-Switch Inverter (NSI) is a recently developed dual output converter. It can be used to drive two three-phase loads independently. As a substitute to two separate conventional voltage source inverters, the NSI has been, already, proposed in various industrial applications to reduce the number of semiconductor switches and its associated energy losses and drive circuitry. On the other hand, the Direct Torque Control (DTC) is a robust control scheme of AC motors, which consist of selecting proper state vectors of a conventional voltage source inverter. The NSI, having a different working principle from the conventional voltage source inverter and taking into account the varying influence of active space vectors on motor's torque and stator flux, a Direct Torque Control is suggested in this paper to, efficiently, drive two induction motors independently, while minimizing the torque and stator flux ripples of both motors. Simulations results confirm the effectiveness of the proposed algorithm. In addition, application of this newly proposed control scheme in operation of an Electric Vehicule (EV) is demonstrated.
\end{abstract}

Copyright $\odot 2018$ Institute of Advanced Engineering and Science. All rights reserved.

\section{Corresponding Author:}

Draoui Abdelghani,

Department of Electrical Engineering,

CAOSEE Laboratory, University of Tahri Mohamed, Bechar, Algeria,

University of Tahri Mohamed, Bechar, B.P 417 Bechar 08000, Algeria.

Email: draoui.abdelghani@gmail.com

\section{INTRODUCTION}

One of the developmental trends, followed by researchers in the field of power electronics, nowadays, is to come up with new converter topologies with a reduced number of semiconductor switches [1]-[3]. These switches represent the most expensive parts of the converter and are responsible, to a large extent, for the energy losses due to the switching operation. For example, as a substitute of the dual inverter, which consists of two separate two-level inverters connected in parallel, several new topologies has been developed, namely, the B4 inverter [4], the Five Leg Inverter [5] and the Nine Switch Inverter(NSI) [6]. Having the least number of semiconductor switches as compared to the aforementioned inverter topologies, the NSI has been suggested in various industrial applications [7]-[11]. Due to its special working mechanism, this inverter has raised a new challenge, which is the adaptation of the classical control methods developed based on the conventional inverter topologies [12]-[14]. In essence, In order to ensure the independent control of the two NSI loads, this inverter can only supply one of its two loads, at any given instant.

The NSI has been, also, suggested in a DTC control scheme for driving two induction motors [15]. This suggested DTC control scheme consist of controlling the two loads in alternate manner with equal time of supply of both loads. Although this proposed control scheme resulted in a relatively good performance, the varying properties of the inverter's state vectors with the operating condions, will lead to high torque and stator flux ripples, as stated in [16],[17]. As a remedy to this problem, the torque and stator flux errors of 
each motor are calculated and the influence of the NSI space vectors on each motor's torque and stator flux is estimated to select the motor to be supplied, next. The advantage of the newly proposed DTC scheme over the older DTC control scheme will be relevant, when the two motors are operating in different speeds and loading conditions.

In this paper, a new algorithm for a DTC control scheme is suggested, based on selection of the most appropriate inverter state vector. This paper is organized as follows. Section 2 describes the working principle of the Nine-Switch Inverter. Section 3 explains, briefly, the DTC of the induction motor. Section 4 details the analytical studies revealing the properties of active vectors in the different operating conditions. The proposed algorithm for driving two induction motors fed by the NSI will be detailed in Section 5. Section 6 presents results and discussion.

\section{THE NINE SWITCH INVERTER}

The NSI has three lesser switches as compared to the classical dual output inverter, it has been developed by replacing the middle six switches of the classical dual output Inverter by only three switches, both inverters are shown in Figure 1.

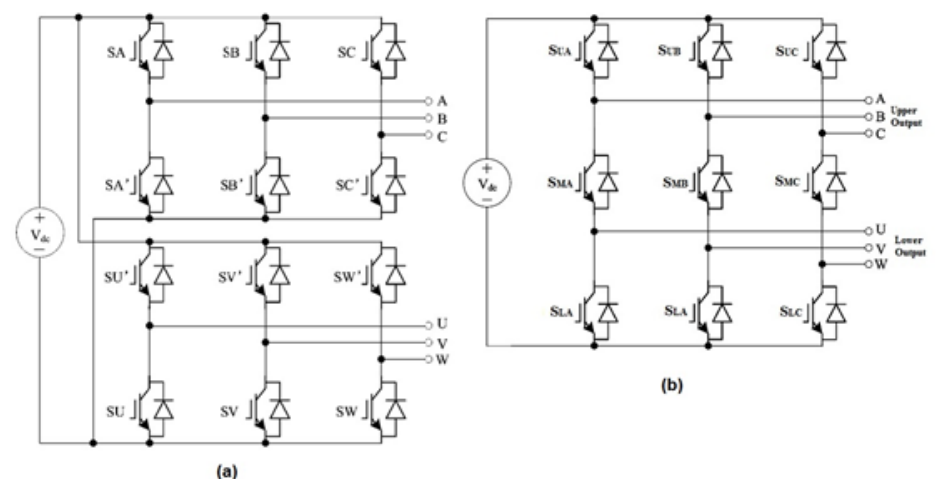

Figure 1. (a) The classical Dual output inverter (b) The NSI

The NSI can be viewed as two two-level inverters operating in alternate manner, the upper six switches constitute a classical six switch VSI, in the other hand, the six lower switches, also, constitute another six switch VSI, hence, the middle three switches are shared between the two sub-inverters. Originally, authors applied the Sinusoidal PWM control scheme, for each leg, the gate signal of the upper switch is generated by comparing the upper half of a triangular carrier signal with a sinusoidal reference signal. The gate signal of the lower switch is generated by comparing the lower half of the same triangular carrier signal with another sinusoidal reference signal. In order to avoid closing the three switches of the same leg simultaneously and therefore shorting the DC source, the gate signal of the middle switch is generated by the output of a XOR logic gate whose inputs are the two gate signals for the upper and lower switches, Figure 2 shows generated gate signals from a carrier signal and two reference signals.

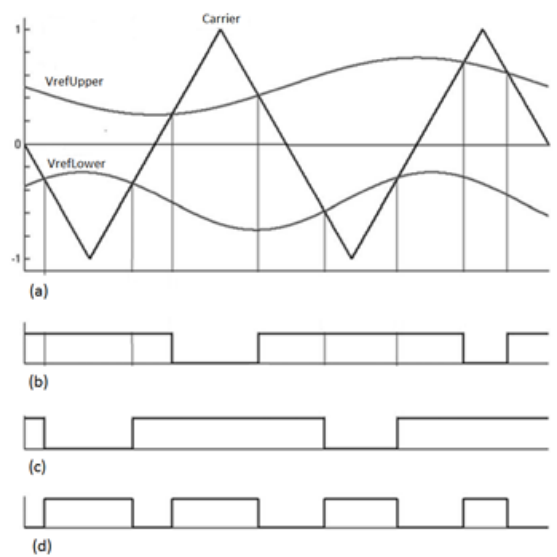


Figure 2. carrier signal, references signals and gate signals of the NSI using SPWM: (a) carrier signal and references signals of upper and lower switches. (b) gate signal of the upper switch reference (c)gate signal of the lower gate signal, (d) gate signal of the middle signal

Each of the three legs of the NSI, is composed of a three switches and only one switch is allowed to be open, at time, in each leg, to avoid : 1- supplying two loads at the same time which will lead to loss of independency of control. 2- keeping terminals of any of the two motors open-circuited, therefore, a combination of 27 switching states are allowed in the control of the Nine Switch Inverter [18].

If two Y-connected loads are to be driven by the NSI, the peak fundamental phase voltage of each load is given as follows:

$$
\mathrm{V}_{\mathrm{an}} \text { peak }(\mathrm{i})=\frac{\mathrm{m}_{\mathrm{i}} \cdot \mathrm{V}_{\mathrm{in}}}{2}
$$

To operate in the linear modulation region of the SPWM, the two reference signals are constrained to stay within the horizontal band of the carrier signal without overlapping, therefore the following inequality has to be, always, satisfied:

$$
m_{1}+m_{2} \leq 1
$$

The reference signals of the $i^{\text {th }}$ load has the following form:

$$
V_{\text {ref }_{i}}=A_{i .} \sin \left(2 \pi . f_{i}\right)+o f f \operatorname{set}_{i}
$$

By manipulating amplitudes and offsets of both sinusoidal reference signals within the carrier signal band, the percentage of use of the DC source is divided accordingly between the two loads. When applying Space Vector Modulation [18], as it is the case of DTC control, a gain of $15 \%$ in the sum of modulation indices, which translate to higher torque production, hence, the inequality condition in equation 2 becomes :

$$
m_{1}+m_{2} \leq \frac{2}{\sqrt{3}}
$$

\section{DIRECT TORQUE CONTROL}

\subsection{Direct Torque Control Technique}

The Direct Torque Control (DTC) has been introduced in the second half of the 1980s [19],[20], although a relatively new control strategy, DTC has quickly gained industrial acceptance [21]. In the conventional DTC scheme, the stator flux and the electromagnetic torque are controlled by proper selection of inverter states vectors.

For proper operation of DTC control scheme, an accurate model for the induction motor is required, since stator flux and the electromagnetic torque are estimated, based the motor model. The two-phase dynamic model of IM in the stationary dq frame:

$$
\begin{aligned}
& V_{s d q}=R_{s} i_{s d q}+\frac{d}{d t}\left(\psi_{s d q}\right) \\
& V_{r d q}=0=R_{r}^{\prime} i_{r d q}+\frac{d}{d t}\left(\psi_{r d q}\right)-j w_{r} \psi_{r d q} \\
& \psi_{s d q}=L_{s} i_{s d q}+L_{m} i_{r d q} \\
& \psi_{r d q}=L_{m} i_{s d q}+L_{r}^{\prime} i_{r d q}
\end{aligned}
$$

Derivative of stator flux is equal to the stator EMF, hence, stator flux magnitude strongly depends on stator voltage.

$$
\frac{d}{d t}\left(\psi_{s d q}\right)=e_{d q}=V_{s d q}-R_{s} i_{s d q}
$$

If voltage drop across $\mathrm{R}_{\mathrm{s}}$ is ignored, stator flux can be controlled by stator voltage applied:

$$
\Delta \psi_{s d q}=\left(V_{s d q}\right) \Delta t
$$


The developed torque is proportional to the sine of angle between stator and rotor flux vectors $\theta_{\mathrm{sr}}$

$$
\begin{aligned}
& \overrightarrow{T_{e}}=\frac{3}{2} \frac{P}{2} \frac{L_{m}}{\sigma L_{s} L^{\prime} r} \overrightarrow{\psi_{r}} \otimes \overrightarrow{\psi_{S}} \\
& \left|T_{e}\right|=\frac{3}{2} \frac{P}{2} \frac{L_{m}}{\sigma L_{s} L^{\prime} r}\left|\boldsymbol{\psi}_{r}\right|\left|\boldsymbol{\psi}_{s}\right| \sin \theta_{s r}
\end{aligned}
$$

Angle of $\overrightarrow{\psi_{\mathrm{S}}}$ is also dependent on stator voltage, hence, $\left|\mathrm{T}_{\mathrm{e}}\right|$ can also be controlled by applying the proper vector to change $\theta_{\mathrm{sr}}$.

\subsection{DTC speed mode control scheme}

The DTC control scheme has two modes of operation, the DTC torque mode where motor torque is controlled directly and the DTC speed mode where motor torque is controlled via motor speed. The DTC speed mode control scheme is shown in Figure 3.

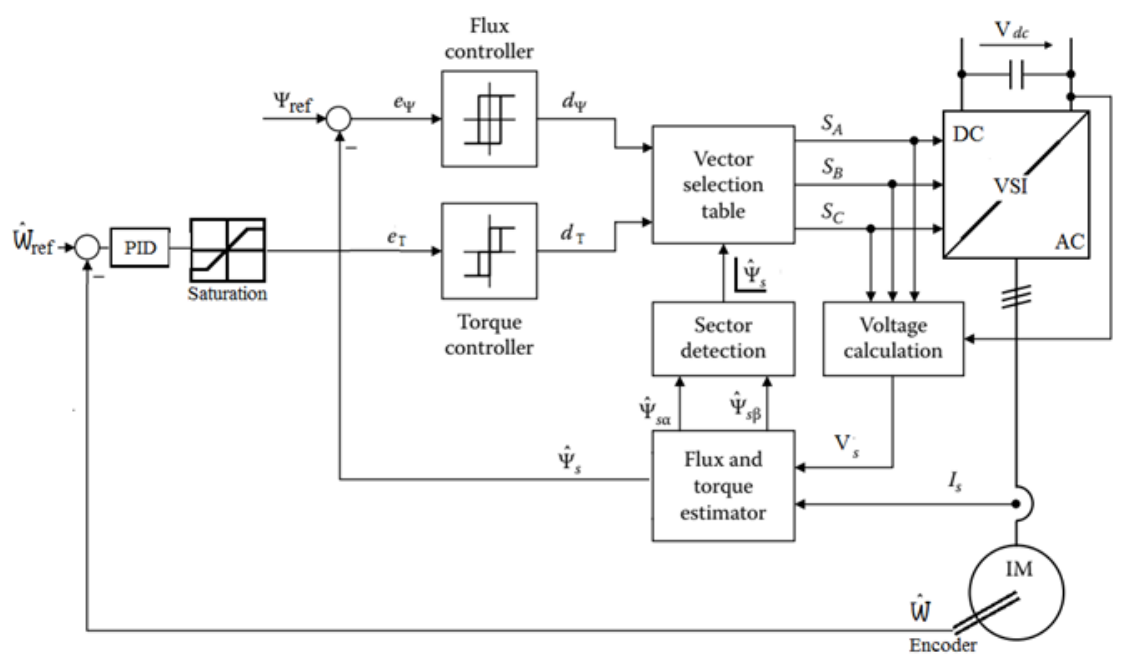

Figure 3. The DTC speed mode control scheme

In the DTC speed mode control scheme, three phase stator currents, stator voltages are measured, motor speed is estimated or measured using an encoder. Stator flux magnitude and angle are estimated from the obtained currents and voltages.

Measured or estimated speed and measured stator flux amplitude are compared with their respective reference values. The stator flux error is fed directly to a hysteresis controller, where the motor speed error is fed to a PI controller then the output of this latter is fed to another hysteresis controller. The output of hysteresis controllers along with the stator flux angle will yield the proper vector to supply according to a predefined switching table.

\subsection{Adaptation of DTC control scheme for use with the NSI}

For an independent control of the two loads, the NSI can only supply one of its two loads at a time, when one load is supplied, the phases of the second load are short-circuited through one of the DC rails. In a DTC point of view, when an active state vector is applied to the inverter composed of the upper six switches, a zero vector is applied to the inverter composed of the six lower switches. While the effect of an active vector on stator flux and torque depends on stator flux space vector position, the zero vector has little effect on flux but it will reduce the torque [22]. This property justify the priority of controlling the torque over the control of stator flux in the proposed algorithm.

In [15], authors suggested a DTC control scheme for two induction motors fed by the NSI as shown in Figure 4, where the two motors are fed in alternate manner with equal time of supply, however, analytical studies performed by [23], show that the rate of increase and the rate of decrease in both torque and stator flux values are not equal for every two successive switchings and therefore controlling the two motors in 
alternate manner with $50 \%$ duty cycle, does not, necessarily, guarantee optimal results, as it will cause asymmetry and high ripples.

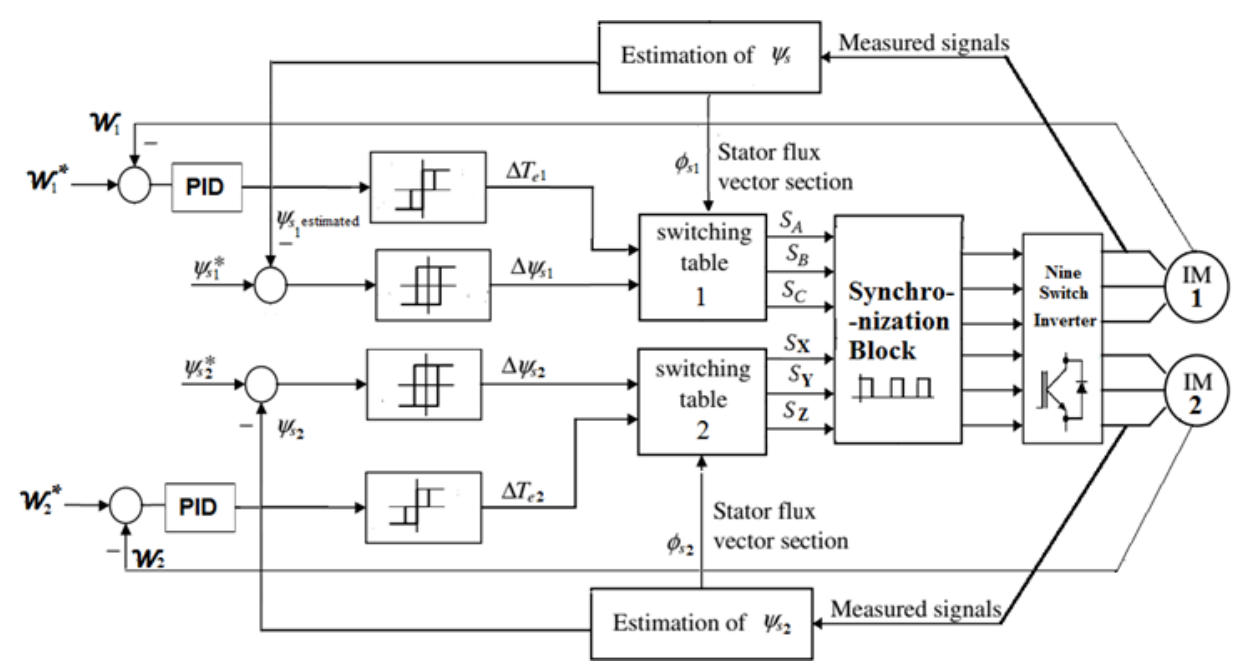

Figure 4. The proposed DTC control scheme in [15] using the NSI

The control scheme proposed by authors is very similar to the conventional control scheme shown in Figure 3, the only difference is that when a variable $S_{A}, S_{B}$ and $S_{C}$ are assigned by the switching Table 1 the synchronization block set all variable $S_{X}, S_{Y}$ and $S_{Z}$ to zero for $50 \%$ of the sampling time, for the other half of the sampling time $S_{A}, S_{B}$ and $S_{C}$ are set to one while $S_{X}, S_{Y}$ and $S_{Z}$ are assigned by the switching Table 2.

\section{TORQUE AND STATOR FLUX RATES OF CHANGE}

\subsection{Rate of change in motor torque}

In the conventional switching selection method [23], the increase and decrease in torque rates vary with the speed of motor,

$$
\begin{aligned}
& \Delta T_{e} \uparrow=\left[P\left(\overrightarrow{\psi_{r}} \otimes \overrightarrow{v_{s}}\right)-P w_{r} \overrightarrow{\psi_{s}} \circ \overrightarrow{\psi_{r}}-R_{m} T_{e}\right] T_{f} / L_{\sigma} \\
& \Delta T_{e} \downarrow=\left[-P w_{r} \overrightarrow{\psi_{s}} \circ \overrightarrow{\psi_{r}}-R_{m} T_{e}\right] T_{f} / L_{\sigma}
\end{aligned}
$$

Where $\mathrm{T}_{\mathrm{f}}$ is the sampling period, $\otimes$ stands for vector product while ${ }^{\circ}$ denotes the scalar product and $R_{m}=$ $\left(L_{r} R_{s}+L_{s} R_{r}\right) / L_{m} ; L_{\sigma}=\left(L_{s} L_{r}-L_{m}^{2}\right) / L_{m}$

The analysis can be summarized in the Table 1 .

Table 1. Increase and decrease rates in Torque Vs Motor Speed [23]

\begin{tabular}{cccc}
\hline & Low speed region & Medium speed region & High Speed Region \\
\hline $\begin{array}{c}\text { Increase Vs Decrease in } \\
\text { Torque }\end{array}$ & $\left|\Delta \mathrm{T}_{\mathrm{e}} \uparrow\right|>\left|\Delta \mathrm{T}_{\mathrm{e}} \downarrow\right|$ & $\left|\Delta \mathrm{T}_{\mathrm{e}} \uparrow\right| \approx\left|\Delta \mathrm{T}_{\mathrm{e}} \downarrow\right|$ & $\left|\Delta \mathrm{T}_{\mathrm{e}} \uparrow\right|<\left|\Delta \mathrm{T}_{\mathrm{e}} \downarrow\right|$ \\
\hline
\end{tabular}

The asymmetry of torque ripple in the various speed regions, are shown in figures from the experiments conducted by the same authors [23]. From the Table 1 and Figure 5, we can clearly notice that driving the two loads with different speeds, will result in higher and asymmetrical torque errors, therefore, supplying the two motors in alternate manner with an equal time of application will worsen the situation. The proposed algorithm will supply the motor with the higher torque error. 


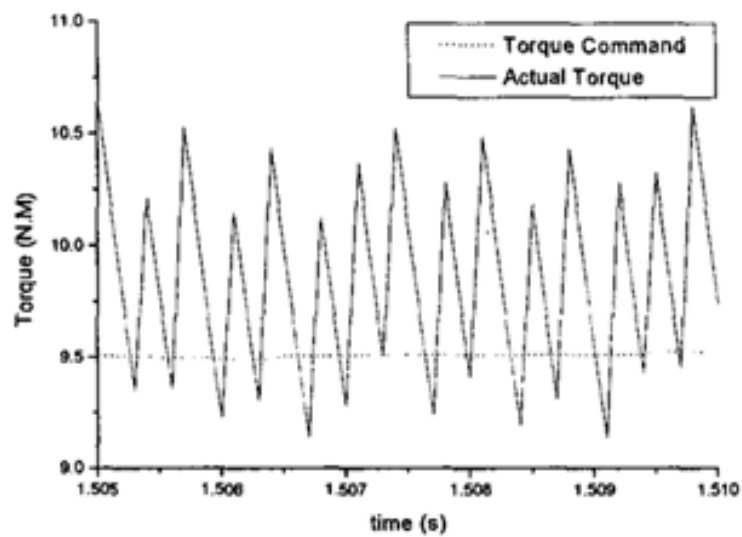

(a)

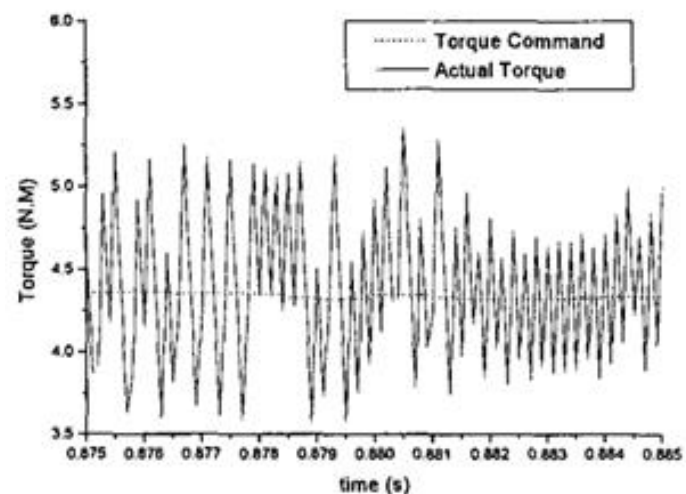

(b)

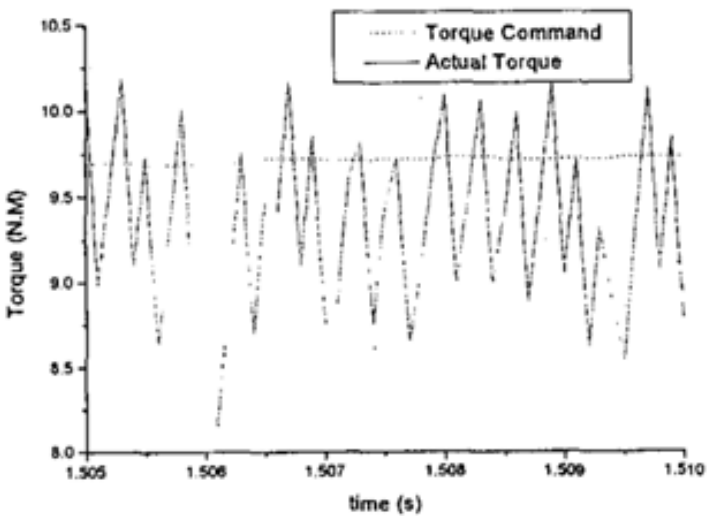

(c)

Figure 5 . Torque ripples in (a) Low Speed Region (b) Medium Speed Region (c) High Speed Region [23]

\subsection{Rate of change in stator flux:}

Given that the angle $\theta\left(\theta \in\left[-30^{\circ}\right.\right.$ to $\left.\left.30^{\circ}\right]\right)$ which is defined as the angle between stator flux space vector $\varphi$ and the active vector $V_{k}$, the effect of the applied active vectors $V_{k+1}$ and $V_{k+2}$ on stator flux are demonstrated in the Table 2 [23]. From the Table 2 and as illustrated in Figure 6, it is evident that selection of vectors near the borders of the sectors will lead to a unbalanced change in stator flux error, which require immediate selection of several active vectors to compensate for the change, therefore, supplying two motors in an alternate fashion with an equal time of application will not help in restoring stator flux to its tolerable values.

Table 2. Influence of vector Vs Stator flux space vector location

\begin{tabular}{ccc} 
& $\theta \approx-30^{\circ}$ & $\theta \approx 30^{\circ}$ \\
\hline $\mathrm{V}_{\mathrm{k}+1}$ applied & small increase & large decrease \\
$\mathrm{V}_{\mathrm{k}+2}$ applied & large increase & small decrease \\
\hline
\end{tabular}




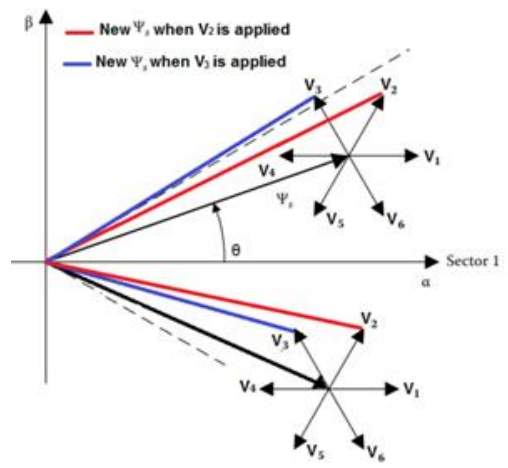

Figure 6. Influence of vector Vs Stator flux space vector location

In the DTC control scheme, in the low speed region, the stator flux ripples are unacceptably high [23]. Findings summarized in Table 2 can be exploited to reduce ripples by selecting the load whose vector have the moderate effect on the stator flux. In other words, the load whose vector is closer to the center of the sector being selected.

\section{THE PROPOSED ALGORITHM}

In order to reduce ripples of the electromagnetic torque and the stator flux in both motors and to ensure a relatively higher switching frequency, the aforementioned facts, are exploited to develop a new control scheme based on the following algorithm (Figure 7):

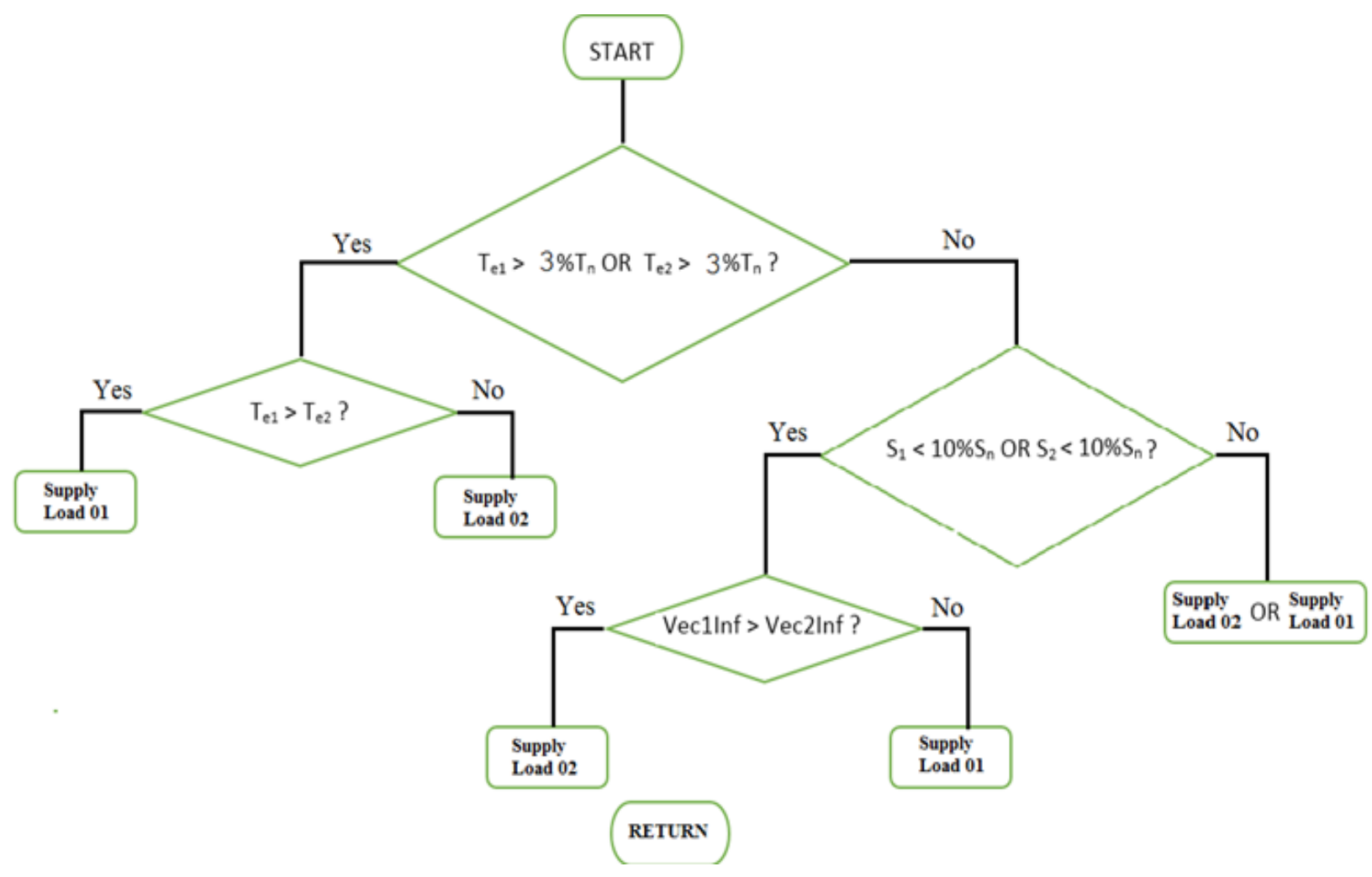

Figure 7. The Flow chart of the developed algorithm

For the reasons stated earlier, control of torque has been given higher priority over the control of stator flux. If any one of the motors or both are having a high torque error, the load with the higher torque error will be supplied by the inverter, in the other hand, if the torque errors of both loads, are acceptable, the 
load whose vector have the least influence on the stator flux change will be selected, in case of operation in the low speed region. Otherwise, the selection is performed in an alternate manner.

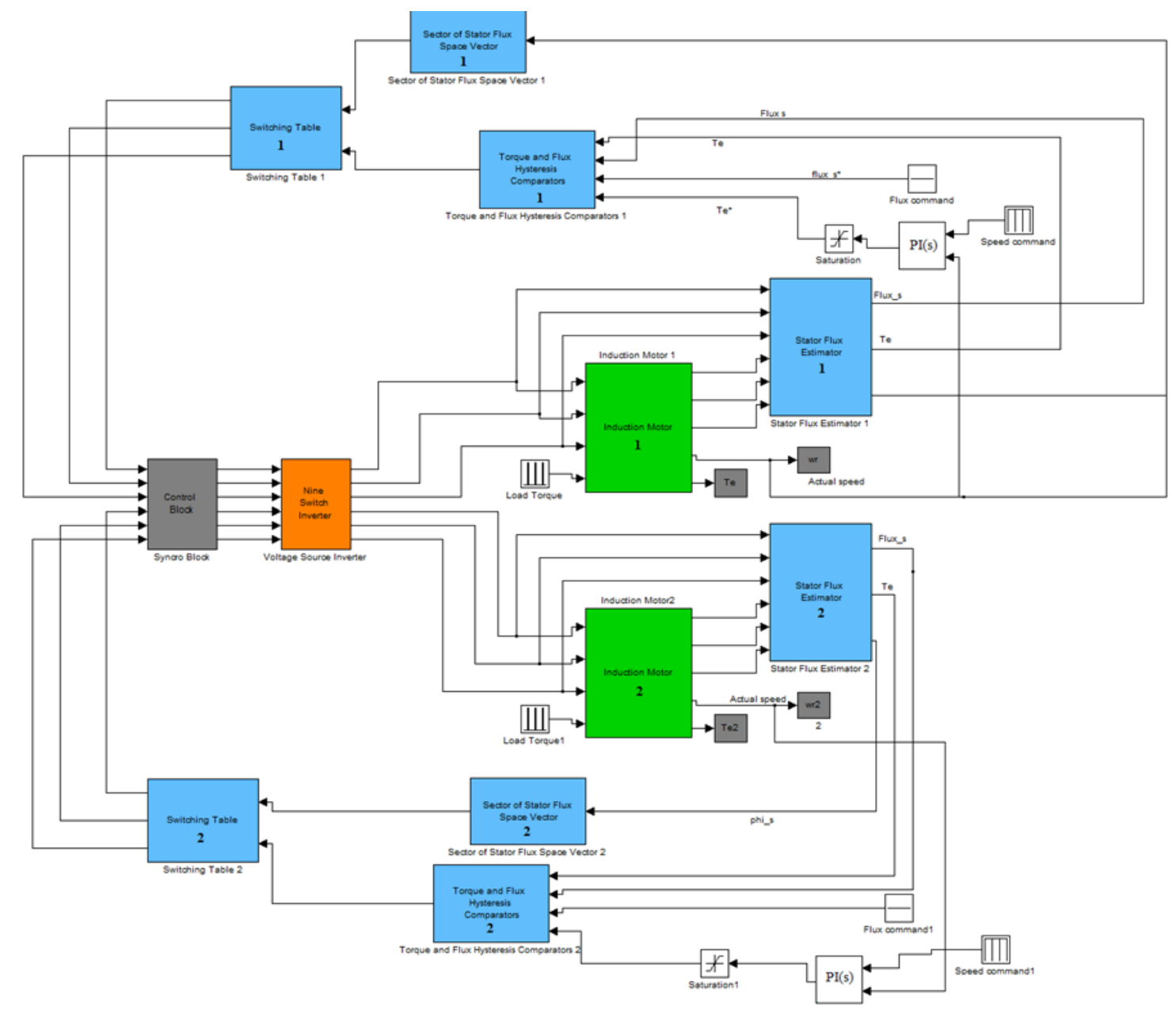

Figure 8. Simulink ${ }^{\circledR}$ Block diagram of the entire System

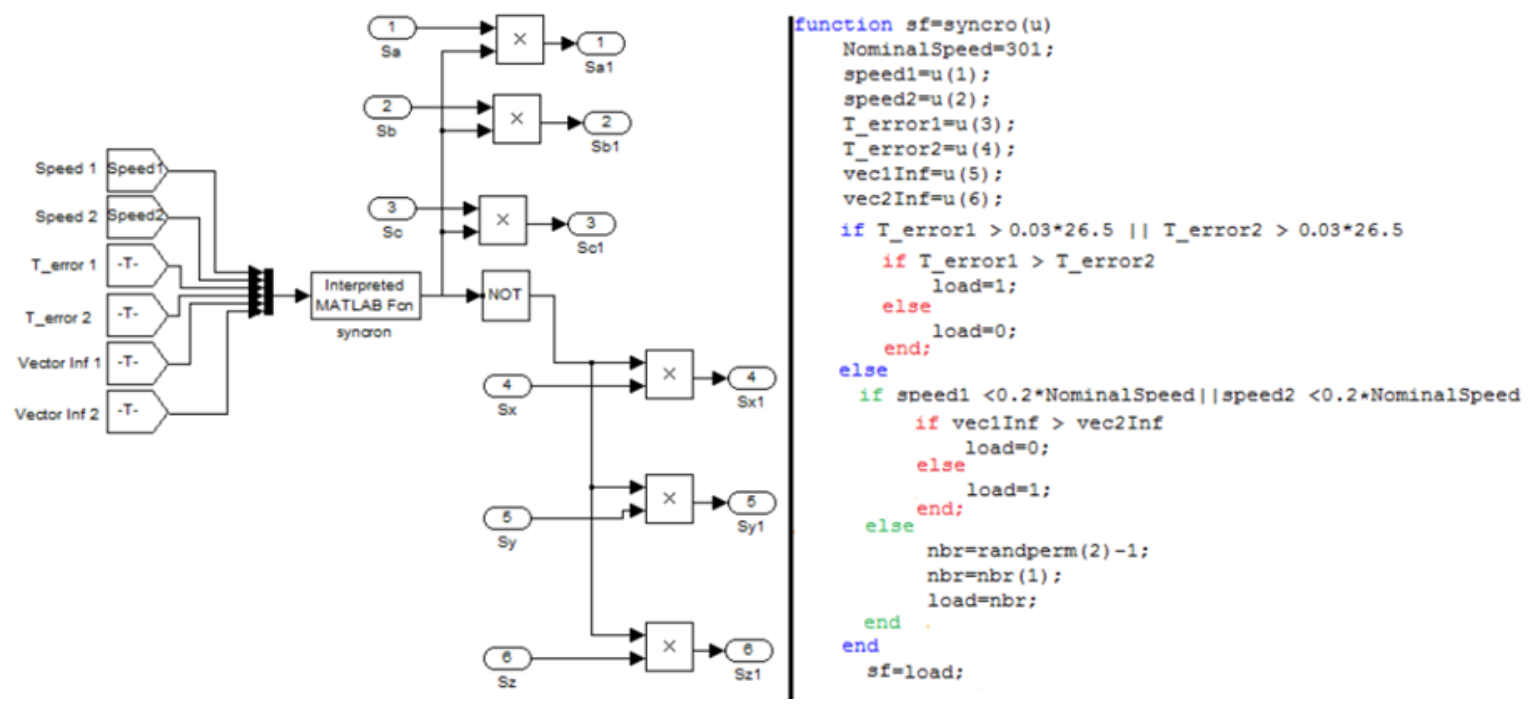

Figure 9. Synchronization Block and Matlab ${ }^{\circledR}$ Function File 


\section{RESULTS AND DISSCUSION}

In order to demonstrate the indpendent control of both motors and to investigate the validity of the proposed algorithm, Simulation using the Matlab/Simulink ${ }^{\circledR}$ software is carried out. Two induction motors are driven with different combinations of speed profiles $(120,300 \mathrm{rad} / \mathrm{s})$, while applying a nominal torque load (26 N.m) in each speed combination, the stator flux of both motor is set to $0.9 \mathrm{~Wb}$.

In the low speed region, the stator flux of each motor has high ripples, this is one of the drawbacks of the original DTC control scheme. the significant voltage drop in stator resistance leads to a poor estimation of stator flux values, hence, a wrong state vector is applied. Several works [24]-[26] has been proposed to have a better estimate of stator flux value. In our proposed control scheme, the algorithm will supply the motor whose active vector has the moderate influence to mitigate the sharp increase of stator flux. Stator flux of the two motors in shown in Figure 10.

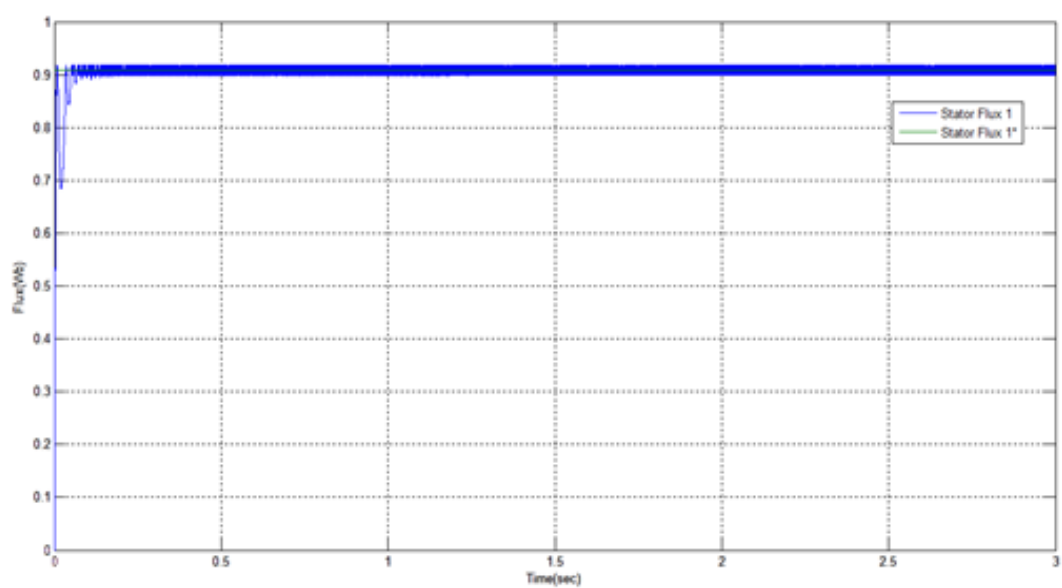

(a)

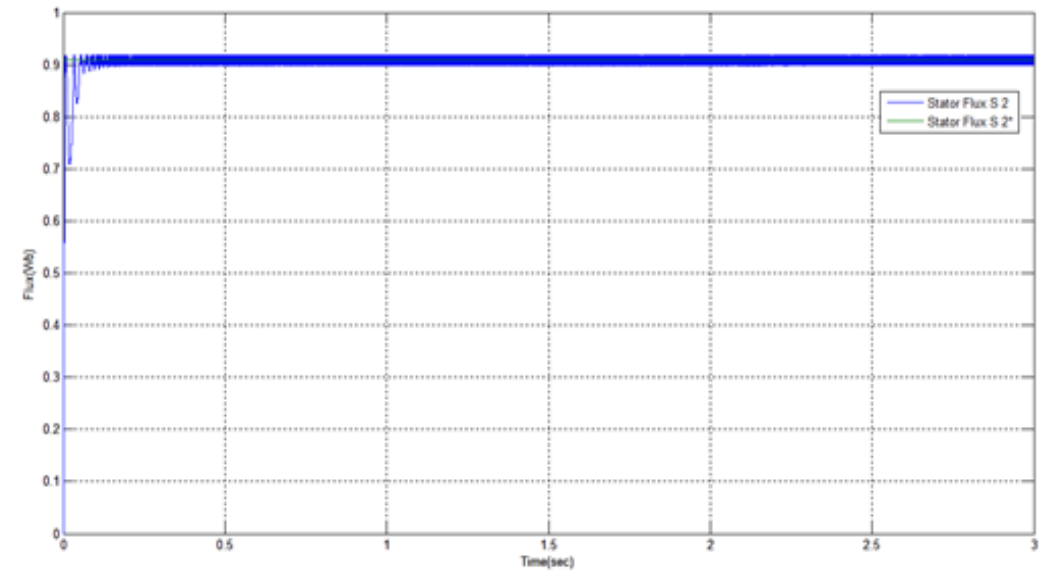

(b)

Figure 10. Stator Flux magnitude of: (a) Motor 1. (b) Motor 2

At first, the speed of the two motors is set to $120 \mathrm{rad} / \mathrm{sec}$ in a time interval of 200 milliseconds, due to this high acceleration rate, $120 \%$ of the nominal torque command is requested by the control system, to reach the assigned speed in time. At time 0.4 seconds, a nominal load is coupled to both motors, the motors torques are increased to keep both motors running at the assigned speed, a slight decrease is noticed (i.e a steady state error $<1 \%$ of the nominal speed). In the medium speed region, the algorithm will control the NSI to supply the load with the larger torque error, Figure 11 and Figure 12 show acceptable torque ripples. 


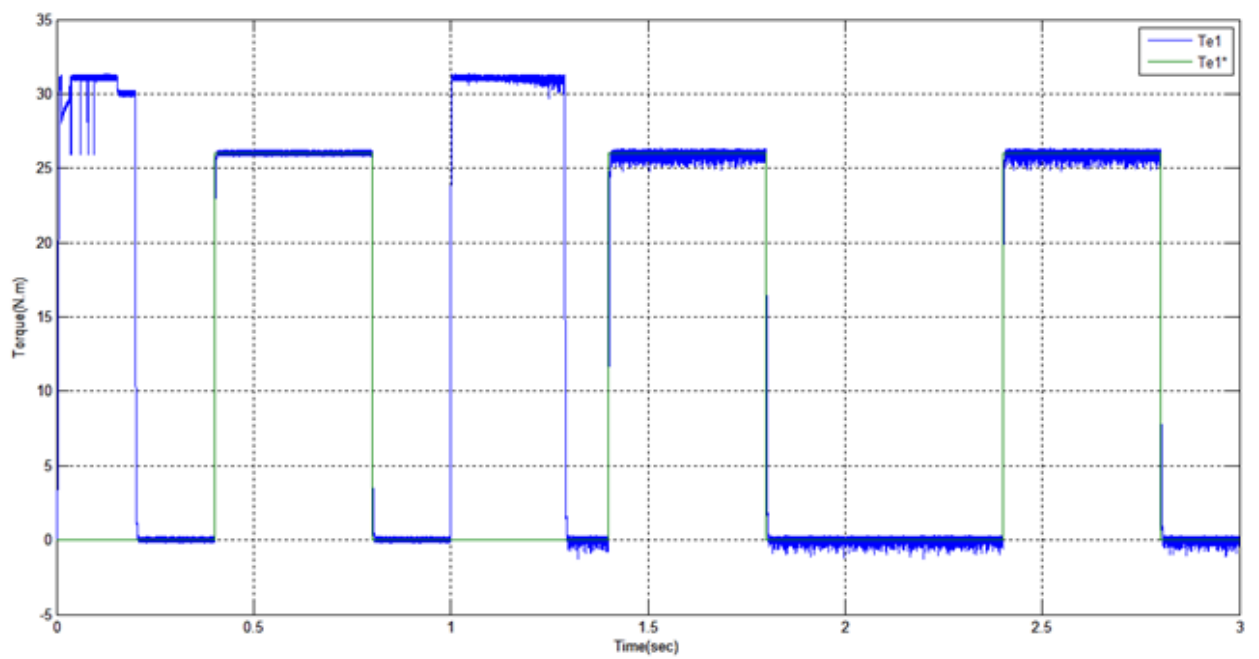

Figure 11. Motor 1 Torque Vs its reference value

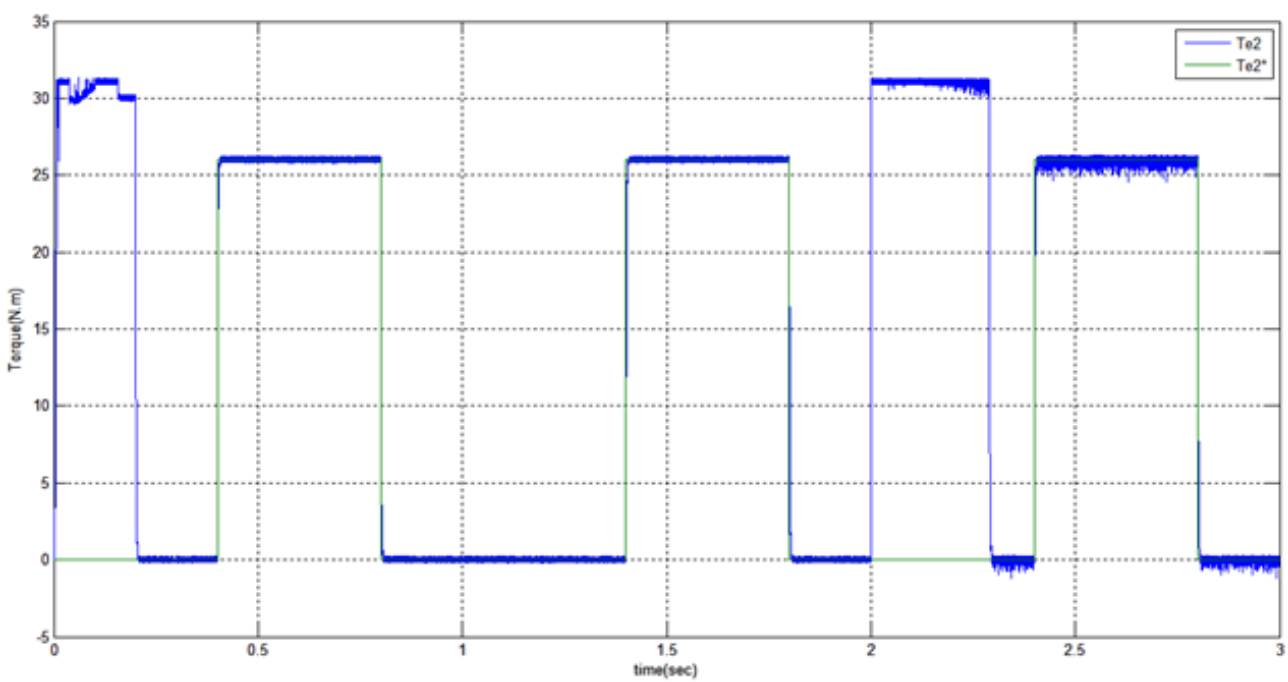

Figure 12. Motor 2 Torque Vs its reference value

After driving both loads with a medium speed, the speed of the first load is increased up to 300 $\mathrm{rad} / \mathrm{sec}$ while the second load is kept running at a medium speed, once again, $120 \%$ of the nominal is produced at the first load to accelerate. a nominal load is applied afterward, Figures 11 and 12 show that the torque ripples of the first load are slightly larger than those of the second load due to the difference in speeds. On the other hand, less than $1 \%$ of steady state error is noticed in speeds of both loads. As stated earlier, based on remarks from Table 1, the torque ripples of the first motor would be higher, if the older control scheme is used.

The speed of the second load is increased to the nominal speed (300 rad/sec) at time $2.0 \mathrm{~seconds}$, a $120 \%$ of nominal torque command is applied to accelerate, a nominal load is applied to both motors, ripples in both stator flux and torque of each motor remains whithin limits, which ensures a good regulation of speed of both motors as shown, in Figures 13 and 14. 


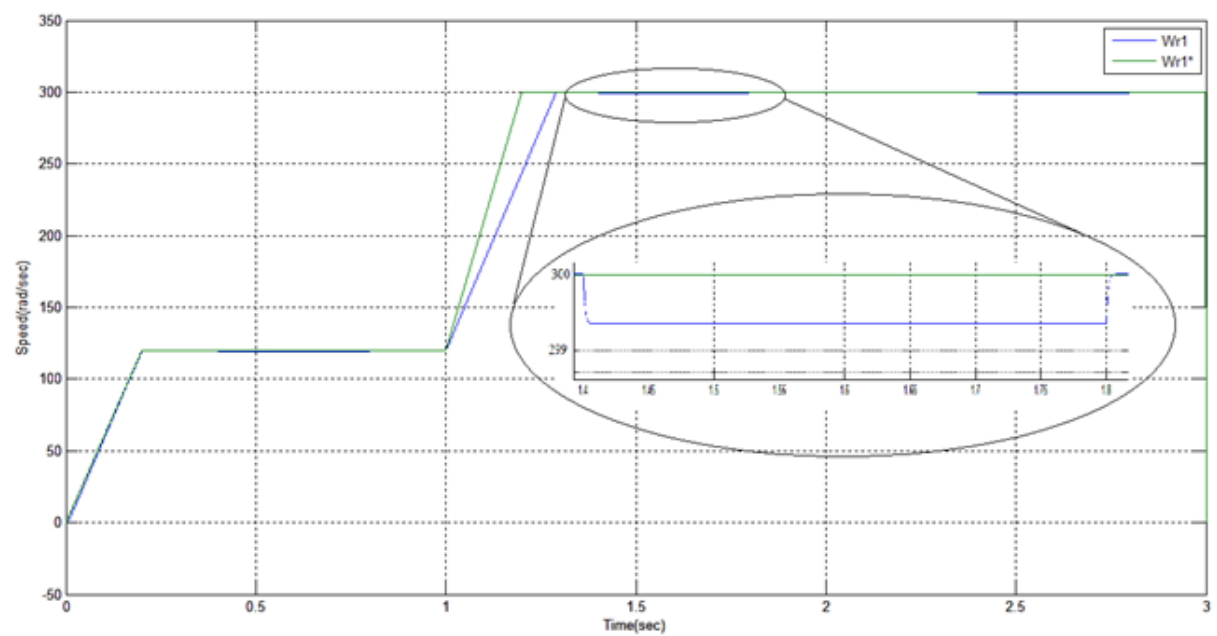

Figure 13. Motor 1 speed Vs its reference value

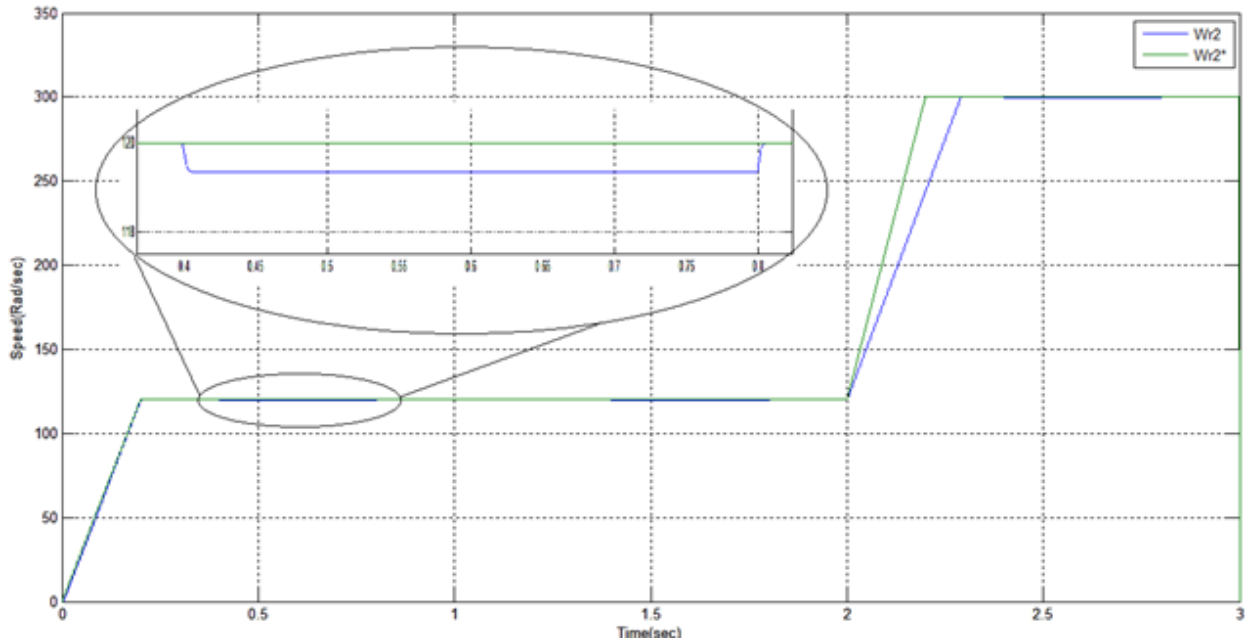

Figure 14. Motor 1 speed Vs its reference value

In the DTC speed mode, the speed of both motors are controlled instead of torques, this facts justify the abrupt rise in torque when acceleration of any of the two motors is requested. A saturation unit is used in the control scheme to avoid forcing the two motors to develop more than $120 \%$ of their nominal torque, In practice, an anti-windup unit is added to the PI controller to compensate for the overshoot inherent in Integral part of the controller [27],[28].

The advantage of the present DTC control scheme over the old DTC control scheme, is evident in two instances, 1- when the two motors are loaded and running at low speeds, inaccurate estimation of stator flux may occur and the alternate selection of active state vectors for the two motors will worsen the performance as it would lead to an abrupt change in stator flux which require application of several active vectors to re-establish stator flux to permissible values. 2- If the old DTC control is opted for, when one of the motors is running at low speed and the other motor is running at high speed, the rate of decrease of torque in the latter motor will be more significant, eventually, leading to abrupt decrease in its speed and a slow response of this motor to reach the assigned speed.

The NSI has been already proposed in Hybrid Electric Vehicle (HEV) [29], similarly, a comprehensive literature review of the DTC control scheme and its application in EV field is detailed in [30] and as demonstrated in the present paper, the combination of DTC control with the use NSI makes it well suited for use in Electric Vehicle EV and HEV applications. The use of the NSI as a substitute to two separate two-level inverters, as shown in Figure 15, will help reduce the overall cost and energy consumption of EVs. 


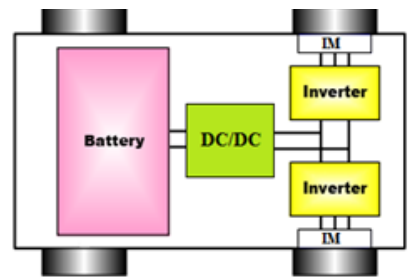

(a)

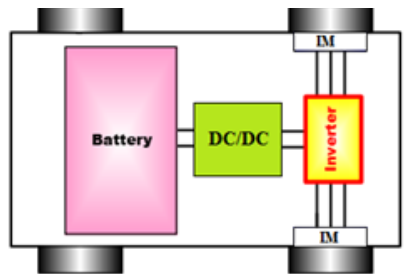

(b)

Figure 14. Topology of: (a) Conventional EV (b) Suggested EV

\section{CONCLUSION}

In this paper, a new Direct Torque control has been developed to drive two induction motors, independently, via the Nine-Switch Inverter. Simulation results show acceptable torque and stator flux ripples for each motor, in different speed profiles. Further improvements can be made, by using the a motor model which takes into account the iron core losses and optimal results can be obtained when more advanced stator flux estimators are used. Being effective in driving two motors with different speed, the NSI has been proved to be well suited for EVs applications.

\section{REFERENCES}

[1] Thiyagarajan V. and Somasundaram P., "A New Level Symmertrical Inverter with Reduced Switch Count," International Journal of Power Electronics and Drive Systems, vol/issue: 9(2) pp. 921-925, 2018.

[2] F. Chouaf and S. Saad, "A New Structure of the Nine Level Inverter Used as Active Power Filter with a Reduced Number of Swiches," International Journal of Power Electronics and Drive Systems, vol/issue: 9(1), pp. 198-209, 2017.

[3] T. Muhammad, et al., "Cascaded Symmetric Multilevel Inverter with Ruduced Number of Controlled Switches," International Journal of Power Electronics and Drive Systems, vol/issue: 8(2), pp. 795-803, 2017.

[4] F. Blaabjerg, et al., "A new optimized space-vector modulation strategy for a component-minimized voltage source inverter,” IEEE Trans. PowerElectron., vol/issue: 12(4), pp. 704-714, 1997.

[5] M. Jones, et al., "Five-leg inverter PWM technique for reduced switch count two-motor constant power applications," IET Electr. Power Appl., vol/issue: 2(5), pp. 275-287, 2008.

[6] T. Kominami and Y. Fujimoto, "A novel nine-switch inverter for independent control of two three-phase loads," Conf. Rec. IEEE IAS Annu.Meeting, pp. 2346-2350, 2007.

[7] M. Heydari, et al., "A Novel Variable-Speed Wind Energy System Using Permanent-Magnet Synchronous Generator and Nine-Switch AC/AC Converter," 1st Power Electronic \& Drive System Technologies Conference (PEDSTC), Tehran, Iran, pp. 5-9, 2010.

[8] C. Liu, et al., "A Novel Three-phase Three-leg AC/AC Converter Using Nine IGBTs," IEEE Transaction on Power Electronic, vol/issue: 24(5), pp. 1151-1160, 2009.

[9] L. R. Limongi, et al., "Dual hybrid power filter based on a nine-switch inverter," Elsevier Electric Power Systems Research, vol. 117, pp. 154-162, 2014.

[10] M. S. Diab, et al., "A nine-switch-converter-based integrated motor drive and battery charger system for EVs using symmetrical six-phase machines," IEEE Trans. Ind. Electron., vol/issue: 63(9), pp. 5326-5335, 2016.

[11] C. A. Reusser, "Full-electric ship propulsion based on a dual nine-switch inverter topology for dual three-phase induction motor drive," 2016 IEEE Transportation Electrification Conference and Expo (ITEC), pp. 1-6, 2016.

[12] D. Abdelghani and A. Boumédiene, "Space Vector Modulation of Quasi-Z Source and Nine-Switch Inverter," Electrotehnica, Electronica, Automatica (EEA), vol/issue: 66(1), pp. 80-86, 2018.

[13] F. Gao, et al., "Optimal pulsewidth modulation of nine-switch converter," Power Electronics, IEEE Transactions on, vol/issue: 25(9), pp. 2331-2343, 2010.

[14] X. Li, et al., "New PWM strategy for nine-switch inverters with minimum number of semiconductor switching," 2014 International Power Electronics and Application Conference and Exposition, pp. 406-410, 2014.

[15] M. Abbache, et al., "Direct torque control of nine switches inverter-dual induction motors," Conf. Rec. IEEE MED, pp. 810-815, 2014.

[16] J. W. Kang and S. K. Sul, "Analysis and prediction of inverter switching frequency in direct torque control of induction machine based on hysteresis bands and machine parameters," IEEE Trans. Ind. Electron., vol. 48, pp. 545-553, 2001.

[17] Casadei D., et al., "Analytical investigation of torque and flux ripple in DTC schemes for induction motors," 23rd International conference on industrial electronics, control and instrumentation (IECON 97), vol. 2, pp. 552-6, 1997.

[18] S. M. Dehghan, et al., "Space vectors modulation for nine-switch converters," IEEE Trans. Power Electron., vol. 25, pp. 1488-1496, 2010.

[19] I. Takahashi and T. Noguchi, "A new quick-response and high-efficiency control strategy of an induction motor," IEEE Trans. Ind. Appl, IA, vol/issue: 22(5), pp. 820-827, 1986. 
[20] M. Depenbrock, "Direct self-control (DSC) of inverter-fed induction motors," IEEE Trans. Power Elect., vol/issue: 3(4), pp. 420-429, 1988.

[21] P. Tiitinen, et al., "The next generation motor control method: Direct torque control (DTC)," Europ. Power Elect. J., vol/issue: 5(1), pp. 14-18, 1995.

[22] N. R. N. Idris and A. H. M. Yatim, "Direct torque control of induction machines with constant switching frequency and reduced torque ripple," IEEE Trans. Ind. Electron., vol/issue: 51(4), pp. 758-767, 2004.

[23] J. Chen and Y. Li, "Virtual vectors based predictive control of torque and flux of induction motor and speed sensorless drives," Conf. Rec. IEEE-IAS Annu. Meeting, pp. 2606-2613, 1999.

[24] I. Alsofyani and N. Idris, "Simple Flux Regulation for Improving State Estimation at Very Low and Zero Speed of a Speed Sensorless Direct Torque Control of an Induction Motor," IEEE Transactions on Power Electronics, vol/issue: 31(4), pp. 3027-3035, 2016.

[25] Y. A. Alamri, et al., "Improved Stator Flux Estimation for Direct Torque Control of Induction Motor Drives," International Journal of Power Electronics and Drive Systems, vol/issue: 7(4), pp. 1049-1060, 2016.

[26] I. Alsofyani and N. R. N. Idris, "Lookup-Table-Based DTC of Induction Machines With Improved Flux Regulation and Extended Kalman Filter State Estimator at Low-Speed Operation," IEEE Transactions on Industrial Informatics, vol/issue: 12(4), pp. 1412-1425, 2016.

[27] M. J. Li and L. Q. Meng, "A New Anti-Windup PI Controller for Direct Torque Control System," TELKOMNIKA Indonesian Journal of Electrical Engineering, vol/issue: 12(7), pp. 5268- 5274, 2014.

[28] F. C. Ferreira, et al., "Anti wind-up techniques applied to real tank level system performed by PI controllers," 20th International Conference on SystemTheory, Control and Computing (ICSTCC), pp. 263-268, 2016.

[29] M. Dehghan, et al., "Hybrid ElectricVehicle based on Bidirectional Z-Source Nine-Switch Inverter," IEEE Transactions on Vehicular Technology, vol/issue: 59(6), pp. 2641-2653, 2010.

[30] T. Sutikno, et al., "A review of direct torque control of induction motors for sustainable reliability and energy efficient drives," Renew Sustain Energy Rev., vol. 32, pp. 548-58, 2014.

\section{NUMENCLATURE}

$\mathrm{L}_{\mathrm{r}} \quad$ : Rotor Inductance refered to the stator

$\mathrm{R}_{\mathrm{r}}$ : : Rotor Resistance refered to the stator

$\mathrm{R}_{\mathrm{s}} \quad$ : Stator Resistance

$\mathrm{L}_{\mathrm{s}} \quad$ : Stator Inductance

$\mathrm{L}_{\mathrm{M}}$ : Mutual Inductance

$\vec{\Psi}_{\mathrm{s}} \quad:$ Stator Flux Space Vector

$\vec{\Psi}_{\mathrm{r}} \quad$ : Stator Flux Space Vector

$\sigma \quad$ : Leakage coefficient.

Parameters of simulated motors:

Line to Line Voltage : $400 \mathrm{~V}$

Number of pole pairs : 2 poles

Stator resistance $: 1.37 \Omega$

Stator inductance $: 0.1459 \mathrm{H}$

Rotor resistance $\quad: 1.1 \Omega$

Rotor inductance $\quad: 0.149 \mathrm{H}$

Mutual inductance $: 0.141 \mathrm{H}$

Moment of Inertia $\quad: 0.1 \mathrm{Kg} / \mathrm{m}^{2}$ 